\title{
Regulation of Collagen V Expression and Epithelial-Mesenchymal Transition by miR-185 and miR-186 during Idiopathic Pulmonary Fibrosis
}

\author{
Guang-Sheng Lei, ${ }^{*}$ Hannah L. Kline, ${ }^{*}$ Chao-Hung Lee, ${ }^{*}$ David S. Wilkes, ${ }^{\dagger}$ and Chen Zhang*
}

From the Department of Pathology and Laboratory Medicine, * Indiana University School of Medicine, Indianapolis, Indiana; and the University of Virginia School of Medicine, ${ }^{\dagger}$ Charlottesville, Virginia

Accepted for publication April 25, 2016.

Address correspondence to Chen Zhang, M.D., Ph.D., Indiana University School of Medicine, $350 \mathrm{~W} 11^{\text {th }} \mathrm{St}$, IUHPL 4084, Indianapolis, IN 46202. E-mail: chenzhan@ iupui.edu.

\begin{abstract}
Idiopathic pulmonary fibrosis is a devastating disease, with no good diagnostic biomarker and limited treatment options. Previous studies suggest that collagen V overexpression and collagen $\mathrm{V}$-mediated immune response play roles in the pathogenesis of idiopathic pulmonary fibrosis. This study aimed to identify dysregulated miRNA-related collagen V overexpression during idiopathic pulmonary fibrosis. We found that the expression levels of miR-185 and miR-186 were decreased in the lungs of idiopathic pulmonary fibrosis patients. The levels of miR-185 and miR-186 were not correlated with disease severity of idiopathic pulmonary fibrosis. The direct regulation of COL5A1 by miR-185 and miR-186 was confirmed by a luciferase reporter assay. Furthermore, mimics of miR-185 and miR-186 blocked transforming growth factor- $\beta$-induced collagen $V$ overexpression and alleviated transforming growth factor- $\beta$-induced epithelial-mesenchymal transition in A549 cells and HCC827 cells. Our findings suggest that attenuated expression of miR-185 and miR-186 may be responsible for collagen $V$ overexpression during idiopathic pulmonary fibrosis, and these miRNAs may serve as pathogenesis-related biomarkers and treatment targets. (Am J Pathol 2016, 186: 2310-2316; http://dx.doi.org/10.1016/ j.ajpath.2016.04.015)
\end{abstract}

Idiopathic pulmonary fibrosis (IPF), which exhibits the pathological pattern of usual interstitial pneumonia (UIP), is the most common and severe form of chronic fibrotic lung disease. The median survival rate of IPF is approximately 3 years. ${ }^{1,2}$ Although there have been new drugs approved by the Food and Drug Administration for controlling symptoms of this disease, lung transplantation remains the only viable intervention for end-stage IPF. ${ }^{3}$ The 5 -year survival rate after lung transplantation is only approximately $46 \% .{ }^{4}$ The cause of IPF is unknown.

Type $\mathrm{V}$ collagen $[\mathrm{Col}(\mathrm{V})]$ is a minor collagen that intercalates within type I collagen, a major collagen in the lung. Col(V) is considered a sequestered antigen in normal lungs and is located in perivascular and peribronchiolar connective tissues. Previous studies show that $\mathrm{Col}(\mathrm{V})$ is overexpressed in the lungs during IPF and that the Col(V)related immune response plays a critical role in the pathogenesis of pulmonary fibrosis. ${ }^{5,6}$ Overexpression of $\mathrm{Col}(\mathrm{V})$ is relatively characteristic of IPF and has been described in only one other disease, obliterative bronchiolitis, which is a fibrotic airway lesion due to chronic rejection of lung transplantation. $^{7-10}$ The mechanism that leads to $\mathrm{Col}(\mathrm{V})$ overexpression is unknown.

miRNAs are regulatory RNAs that suppress gene expression at a posttranscriptional level by binding to the $3^{\prime}$-untranslated region ( $3^{\prime}$-UTR) of a gene. Mature miRNAs are 18 to 24 nucleotide long single-stranded RNAs, which are relatively stable in human tissue and serum, serving as excellent candidates for biomarker development. Advancements in local delivery of miRNAs increase the bioavailability in target tissue and make miRNAs suitable therapeutic

Supported by a Project Development Team within the Indiana Clinical and Translational Sciences Institute (ICTSI), NIH/National Center for Research Resources (NCRR) grant UL1TR001108 (C.Z.).

Disclosures: None declared. 
targets in a number of neoplastic or nonneoplastic conditions. ${ }^{11}$ Expression of a few miRNAs, such as miR-326 and miR-154, have been reported to be altered in the lungs of IPF patients and to play roles in the pathogenesis of fibrosis. ${ }^{12-15}$ Research characterizing distinct IPF-associated miRNAs is still in its infancy. Because overexpression of $\mathrm{Col}(\mathrm{V})$ is a relatively specific phenomenon in IPF, we hypothesize that miRNAs regulating $\mathrm{Col}(\mathrm{V})$ expression show a dysregulated pattern that is specific for IPF, and this altered miRNA expression pattern may serve as a useful pathogenesis-related biomarker and treatment target of IPF.

\section{Materials and Methods}

\section{Patient Selection}

Fifteen IPF patients with a clinical diagnosis of IPF and a pathological diagnosis of UIP on open lung biopsy or lung explant at Indiana University from 2008 to 2013 were retrospectively collected as our study subjects. The patients' demographic information and clinical data were obtained from the electronic medical record. The clinical and histological characteristics of selected patients are summarized in Table 1. Formalin-fixed, paraffin-embedded (FFPE) lung tissue was used for nucleic acid extraction and subsequent analyses. To ensure that tissue blocks selected show a similar level of involvement and stage of fibrosis, all slides were reviewed by a subspecialty-trained pulmonary pathologist (C.Z.) and the tissue selected showed typical pathological features of UIP, which include random patchy distribution of old fibrosis in the form of scar with honeycomb change (no more than $60 \%$ of total area), new fibrosis in the form of fibroblast foci, and uninvolved lung parenchyma (at least $30 \%$ of total area). A representative image of the selected tissue is shown in Figure 1. Normal appearing FFPE lung tissue from age- and sex-matched group of 15 patients was used as the normal control. The study was approved by the Institutional Review Boards in accordance with the Institutional Committee for the Protection of Human Subjects.

\section{Cells, Plasmids, and Antibodies}

Human HEK293 cell line was purchased from ATCC (Manassas, VA) and maintained in Dulbecco's modified Eagle's medium (Invitrogen, Carlsbad, CA) with 10\% fetal bovine serum (Sigma-Aldrich, St. Louis, MO). Human lung alveolar epithelial cell lines A549 and HCC827 were also purchased from ATCC and maintained in F-12K medium (Gibco Products, Invitrogen) with 10\% fetal bovine serum. The COL5A1 3'-UTR luciferase reporter plasmid and miRNA mimics were purchased from Active Motif (Carlsbad, CA). The predicted miR-185 binding site located in the position 1502 to 1509 of COL5A1 3'-UTR and the predicted miR-186 binding site located in the position 2245 to 2251 of COL5A1 3'-UTR were mutated by a substitution of $4 \mathrm{bp}$ using the QuickChange Site-Directed Mutagenesis Kit from Agilent Technologies Inc. (Santa Clara, CA). The miRNA mimics are chemically optimized synthetic double-stranded RNAs that act as functional equivalents to endogenous human miRNAs. Antibodies against $\mathrm{Col}(\mathrm{V})$, E-cadherin (E-cadherin), $\alpha$-smooth muscle actin ( $\alpha$-SMA), and glyceraldehyde-3-phosphate dehydrogenase were obtained from Cell Signaling Technology Inc. (Beverly, CA).

\section{Real-Time PCR Assay}

Total RNA was isolated from a $10-\mu \mathrm{m}$ scroll of FFPE lung tissue using the miRNeasy FFPE kit (Qiagen), and 100 ng of

Table 1 Clinical and Histological Characteristics of Patients with IPF/UIP

\begin{tabular}{|c|c|c|c|c|c|c|c|}
\hline Case no. & Age (years) & Sex & Smoking status & $\begin{array}{l}\text { Time frame between } \\
\text { initial symptom } \\
\text { and biopsy (month) }\end{array}$ & FVC (\%) & $\begin{array}{l}\text { Biopsy } \\
\text { tissue type }\end{array}$ & $\begin{array}{l}\text { Degree } \\
\text { of fibrosis* }\end{array}$ \\
\hline 2 & 62 & $\mathrm{~F}$ & Nonsmoker & 120 & $1.09(41)$ & Explant & 3 \\
\hline 3 & 55 & $M$ & Former smoker & 108 & $1.84(41)$ & Explant & 3 \\
\hline 4 & 67 & M & Former smoker & 96 & $2.2(55)$ & Explant & 3 \\
\hline 7 & 64 & M & Nonsmoker & 22 & $1.17(32)$ & Explant & 2 \\
\hline 8 & 65 & $M$ & Former smoker & 10 & $1.63(45)$ & Explant & 2 \\
\hline 9 & 77 & $M$ & Former smoker & 30 & $2.35(58)$ & Wedge & 2 \\
\hline 10 & 46 & $M$ & Former smoker & 30 & $1.85(35)$ & Explant & 3 \\
\hline 11 & 72 & $\mathrm{~F}$ & Nonsmoker & 4 & NA & Wedge & 3 \\
\hline
\end{tabular}

*Degree of fibrosis: $1=0 \%$ to $25 \%, 2=26 \%$ to $50 \%, 3=51 \%$ to $100 \%$.

F, female; M, male; FVC, forced vital capacity; IPF, idiopathic pulmonary fibrosis; NA, not available; UIP, usual interstitial pneumonia. 

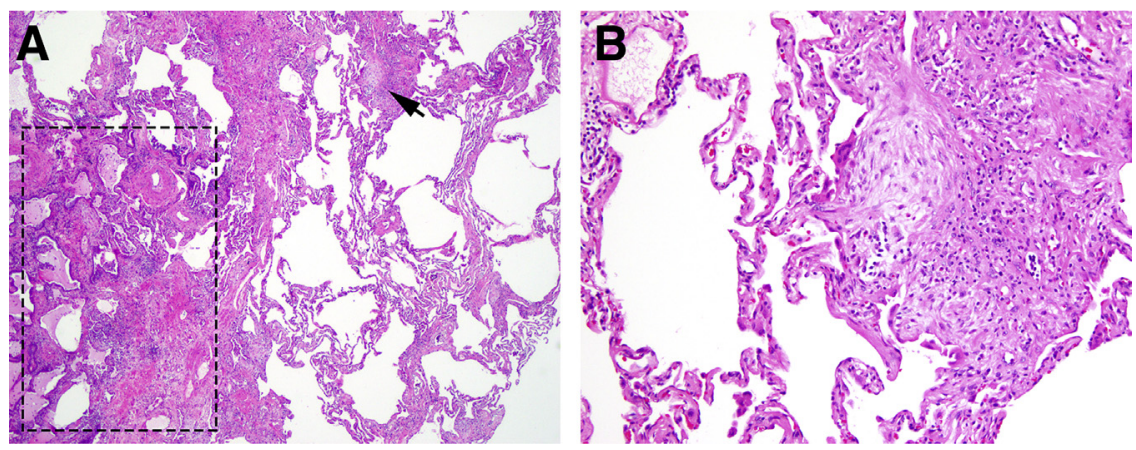

Figure 1 Representative images of the tissue selected for miRNA analysis. A: The tissue blocks selected show typical histopathological pattern of usual interstitial pneumonia: patchy distribution of old fibrosis in the form of scar and honeycomb change (boxed area), and new fibrosis in the form of fibroblast focus (arrow), next to nonfibrotic lung parenchyma. Hematoxylin and eosin (H\&E) was used. B: An enlarged image of a fibroblast focus depicted by the arrow in A. H\&E was used. Original magnification: $\times 40(A) ; \times 100(B)$.

total RNA from each sample was used for reverse transcription using the iScript cDNA synthesis kit (Bio-Rad, Hercules, CA). Real-time RT-PCR for miRNAs was performed on a RotorGene Q (Qiagen) with a miScript Primer Assay and the miScript SYBR Green PCR Kit (Qiagen). The miRNA internal control $\mathrm{Ct}$ value for each sample was the average value of five individual assays using primers of the five small nucleolar RNAs (SNORD61, SNORD68, SNORD72, SNORD95, and SNORD96A). All PCRs were performed in triplicate. Data from each sample were normalized to the miRNA internal control and were shown as fold change relative to the mean of control group using the $2^{-\Delta \Delta \mathrm{Ct}}$ method.

\section{Luciferase Reporter Assay of Candidate miRNAs}

HEK293 cells were cotransfected with miRNA mimic or nontargeting control miRNA and the LightSwitch $3^{\prime}$-UTR Reporter GoClone (Active Motif), using Dharma-FECT Duo transfection reagent (Dharmacon, T-2010-01). Twenty-four hours after transfection, cells were lysed, and luciferase activity of cell lysates was determined by using the LightSwitch Luciferase Assay Reagent (Active Motif) and a luminometer. Each transfection experiment was independently repeated three times. The means and SDs of luciferase activity were calculated and compared between the miRNA mimic group and control group.

\section{A549 Cell and HCC827 Cell Transfection and TGF- $\beta$ Induction}

The night before transfection, $5 \times 10^{4}$ cells were seeded in each well of a 96-well plate and incubated overnight at $37^{\circ} \mathrm{C}$ and $5 \% \mathrm{CO}_{2}$. The cells were then transfected with miRNA mimics or control miRNAs using Dharma-FECT Duo transfection reagent (Dharmacon). Six hours after transfection, the medium was replaced with complete medium containing 10 $\mathrm{ng} / \mathrm{mL}$ of transforming growth factor (TGF)- $\beta$ (R\&D Systems, Minneapolis, $\mathrm{MN}$ ) or vehicle control. The cells were further incubated for 24 hours at $37^{\circ} \mathrm{C}$ and $5 \% \mathrm{CO}_{2}$.

\section{Western Blot Analysis}

After 24 hours of TGF- $\beta$ induction, the cells were washed twice with ice-cold phosphate-buffered saline and lysed with a protein extraction buffer (radioimmunoprecipitation assay buffer: $25 \mathrm{mmol} / \mathrm{L}$ Tris-HCl, pH 7.6, $150 \mathrm{mmol} / \mathrm{L}$ $\mathrm{NaCl}, 1 \% \mathrm{NP}-40,1 \%$ sodium deoxycholate) containing $1 \%$ protease inhibitor cocktail (Sigma). Protein concentration was determined by using the RC DC protein assay kit (BioRad). Equal amounts of protein from each sample were electrophoresed in a $10 \%$ sodium dodecyl sulfate (SDS) polyacrylamide gel. Protein levels of E-cadherin, $\alpha$-SMA, and $\mathrm{Col}(\mathrm{V})$ were determined by Western blotting using respective antibodies and were normalized to that of glyceraldehyde-3-phosphate dehydrogenase. Densitometry analysis of results on X-ray films was performed by using ImageJ software version $1.50 \mathrm{c} 4$ (NIH, Bethesda, MD; http://rsb.info.nih.gov/ij). The density ratio of E-cadherin to $\alpha$-SMA was calculated and compared among groups.

\section{Statistical Analysis}

Continuous data were presented as means \pm SDs of the indicated number of specimens/experiments. Differences between groups were determined using the two-tail Mann-Whitney test and were considered statistically significant if $P$ was $<0.05$. Statistical analysis was performed using the Prism software version 6.0C (GraphPad Software, Inc., La Jolla, CA).

\section{Results}

\section{Expressions of miR-185 and miR-186 Is Attenuated} during IPF

Col(V) exists in the lung as a heterotrimer of two $\alpha 1$ chains and one $\alpha 2$ chain. The physiological activity of this heterotrimer is mainly attributed to the NH2-terminal $30-\mathrm{kDa}$ fragment of $\alpha 1$, which is encoded by the gene COL5A1. ${ }^{16} \mathrm{~A}$ list of COL5A1-targeting miRNAs that are conserved among mammals (Table 2) was generated using Target Scan Human software version 5.2 (Whitehead Institute for Biomedical Research, Cambridge, MA; http://www. stargetscan.org) and the resources from http://www. microRNA.org (last accessed April 20, 2016). Expression level of each of the 23 miRNAs in the FFPE lung tissue was determined by real-time RT-PCR and compared between IPF and control groups. The $P$ values between IPF and control groups are listed in Table 2. Results showed that 
Table 2 COL5A1 Targeting miRNAs Conserved among Mammals and Their $P$ Values between IPF and Control Groups

\begin{tabular}{|c|c|c|c|c|c|c|c|c|c|c|}
\hline \multirow[b]{2}{*}{ miRNA } & \multicolumn{4}{|c|}{ Conserved sites } & \multicolumn{4}{|c|}{ Poorly conserved sites } & \multirow[b]{2}{*}{ Total context score } & \multirow[b]{2}{*}{$P$ value } \\
\hline & Total & $8 \mathrm{mer}$ & 7 mer-m8 & 7 mer-1A & Total & 8 mer & 7 mer-m8 & 7 mer-1A & & \\
\hline miR-185-5p & 0 & 0 & 0 & 0 & 1 & 1 & 0 & 0 & -0.08 & $0.005^{*}$ \\
\hline miR-4306 & 0 & 0 & 0 & 0 & 1 & 1 & 0 & 0 & -0.08 & 0.057 \\
\hline miR-495-5p & 1 & 0 & 1 & 0 & 0 & 0 & 0 & 0 & -0.02 & 0.111 \\
\hline miR-379-5p & 0 & 0 & 0 & 0 & 1 & 0 & 0 & 1 & -0.05 & 0.115 \\
\hline miR-874-3p & 0 & 0 & 0 & 0 & 1 & 0 & 1 & 0 & -0.04 & 0.190 \\
\hline miR-491-5p & 0 & 0 & 0 & 0 & 1 & 0 & 1 & 0 & -0.11 & 0.198 \\
\hline $\operatorname{miR}-488-5 p$ & 0 & 0 & 0 & 0 & 1 & 0 & 0 & 1 & -0.01 & 0.198 \\
\hline $\operatorname{miR}-125 a-3 p$ & 0 & 0 & 0 & 0 & 1 & 0 & 0 & 1 & -0.10 & 0.229 \\
\hline $\operatorname{miR}-874-5 p$ & 0 & 0 & 0 & 0 & 1 & 0 & 1 & 0 & -0.04 & 0.247 \\
\hline miR-379-3p & 0 & 0 & 0 & 0 & 1 & 0 & 0 & 1 & -0.05 & 0.645 \\
\hline miR-544a & 1 & 1 & 0 & 0 & 0 & 0 & 0 & 0 & -0.37 & 0.661 \\
\hline miR-543 & 1 & 0 & 1 & 0 & 1 & 0 & 0 & 1 & -0.03 & 0.765 \\
\hline miR-539-5p & 0 & 0 & 0 & 0 & 1 & 1 & 0 & 0 & -0.03 & 0.859 \\
\hline miR-873-3p & 0 & 0 & 0 & 0 & 1 & 1 & 0 & 0 & -0.10 & 0.924 \\
\hline miR-873-5p & 0 & 0 & 0 & 0 & 1 & 1 & 0 & 0 & -0.10 & 0.956 \\
\hline $\operatorname{miR}-1193-5 p$ & 0 & 0 & 0 & 0 & 1 & 0 & 0 & 1 & -0.05 & 0.959 \\
\hline
\end{tabular}

${ }^{*} P<0.05$, compared to the control group.

IPF, idiopathic pulmonary fibrosis.

expression levels of miR-185 and miR-186 in IPF lungs were significantly decreased compared with those in normal lungs $(P=0.005$ and $P=0.006$, respectively) (Figure 2 ). The expression levels of miR-185 (correlation coefficient $r=0.14, P=0.67$ ) and miR-186 (correlation coefficient $r=0.11, P=0.74$ ) did not correlate with disease severities of IPF as indicated by patients' forced vital capacity.

\section{COL5A1 Is a Direct Target of miR-185 and miR-186}

To determine whether miR-185 and miR-186 regulate the translation of COL5A1, HEK293 cells were transiently
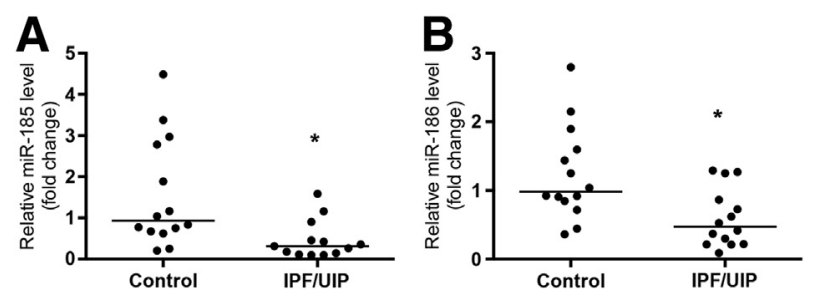

Figure 2 Decreased expression levels of miR-185 (A) and miR-186 (B) in the lungs from patients with idiopathic pulmonary fibrosis (IPF)/usual interstitial pneumonia (UIP). Total RNA was isolated from formalin-fixed, paraffin-embedded lung tissue from 15 patients with IPF and 15 controls. The expression levels of miR-185 and miR-186 were determined by real-time RT-PCR and were normalized to those of the internal control. Fold change relative to the mean of control group was calculated for each specimen and is shown in a dot-plot form. ${ }^{*} P<0.05$ versus control. transfected with synthetic miRNA mimics and a wild-type or mutant (Figure 3A) 3'-UTR Reporter GoClone containing a constitutively expressed luciferase reporter gene fused with COL5A1 $3^{\prime}$-UTR. Functional miRNA mimics that directly bind to COL5A1 3'-UTR should decrease the transcript stability and/or translational efficiency of the luciferase reporter gene, leading to decreased luciferase activity in the cell lysates. The cells transfected with mimics of miR185 or miR-186 showed significantly decreased levels of luciferase activities, compared with the cells transfected with nontargeting control miRNA $(P=0.009$ and $P=0.005$, respectively) (Figure $3 \mathrm{~B}$ ). This result suggests that miR-185 and miR-186 bind to the $3^{\prime}$-UTR of COL5A1. The bindings of miR-185 and miR-186 were specific because the COL5A1 3'-UTR with mutations of predicted binding sites did not respond to the corresponding mimics (Figure 3B).

Mimics of miR-185 and miR-186 Block TGF- $\beta$-Induced Col(V) Overexpression in A549 Cells and HCC827 Cells

A549 cells expressed low levels of Col(V), and about ninefold increase of $\mathrm{Col}(\mathrm{V})$ protein expression was seen after 24 hours of TGF- $\beta$ induction (Figure 4, A and B). To investigate whether miR-185 and miR-186 regulate TGF$\beta$-induced col $(\mathrm{V})$ protein overexpression, miR-185 and miR-186 mimics were transfected into A549 cells 6 hours 
A

Position 1502-1509 of COL5A1 3'-UTR 5'-UCUCUCC

IIIIII I

hsa-miR-185-5p 3'-AGAGAGG

185 mutant-COL5A1 3'-UTR 5'-UGAGACC

Position 2254-2251 of COL5A1 3'-UTR 5'-AUUCUUU

IIIIII

hsa-miR-186-5p 3'-UAAGAAA

186 mutant-COL5A1 3'-UTR 5'-AAAGAUU

\section{B}

$\begin{array}{llllll}\text { Wild-type } & + & + & + & - & - \\ 185 \text { mutant } & - & - & - & + & - \\ 186 \text { mutant } & - & - & - & - & + \\ \text { miR-185 mimic } & + & - & - & + & - \\ \text { miR-186 mimic } & - & + & - & - & + \\ \text { Nontargeting miR } & - & - & + & - & -\end{array}$

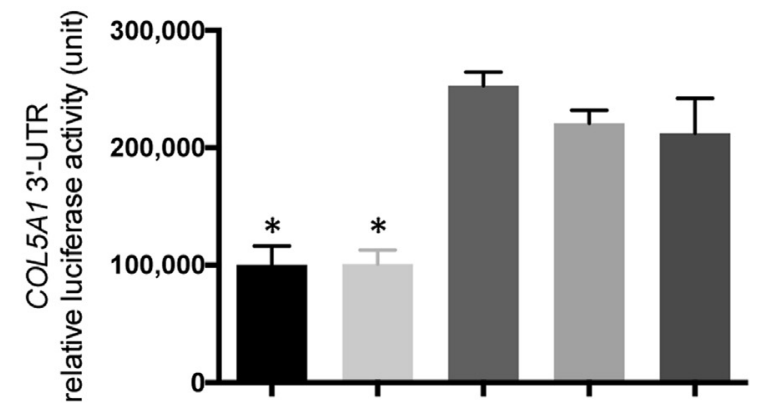

Figure 3 miR-185 and miR-186 directly regulate COL5A1 gene. A: Predicted bindings of miR-185 and miR-186 to the $3^{\prime}$-untranslated region (UTR) of COL5A1 and introduction of a $4 \mathrm{bp}$ mutation for ensuring specificity. The bold letters represent the 4 bp substitutions in the mutant clones of COL5A1 3'-UTR. B: HEK293 cells were cotransfected with the wild-type or mutant LightSwitch 3'-UTR Reporter GoClone and miR-185 mimic, miR-186 mimic, or nontargeting control miRNA. The luciferase activity was determined 24 hours after transfection. The means and SDs of luciferase activity were calculated from three independent experiments. ${ }^{*} P<0.05$ versus control.

before TGF- $\beta$ induction. The results showed that transfection of miR-185 or miR-186 mimics lead to a near complete blockage of TGF- $\beta$-induced $\mathrm{Col}(\mathrm{V})$ overexpression in A549 cells. Transfection of the control nontargeting miRNA had no effect on TGF- $\beta$-induced $\mathrm{Col}(\mathrm{V})$ overexpression (Figure 4, A and B). The same experiment was repeated using HCC827 cells with similar results (Supplemental Figure S1).

Mimics of miR-185 and miR-186 Alleviate TGF$\beta$-Induced EMT in A549 Cells and HCC827 Cells

Epithelial-mesenchymal transition (EMT), which is characterized by loss of epithelial marker E-cadherin and acquisition of mesenchymal marker $\alpha$-SMA, plays pathogenesis roles in IPF. The TGF- $\beta$-induced EMT cell culture model was used to explore the possible roles of miR-185 and miR-186 in EMT. TGF- $\beta$ induction caused approximately $80 \%$ reduction in the ratio of E-cadherin to $\alpha$-SMA

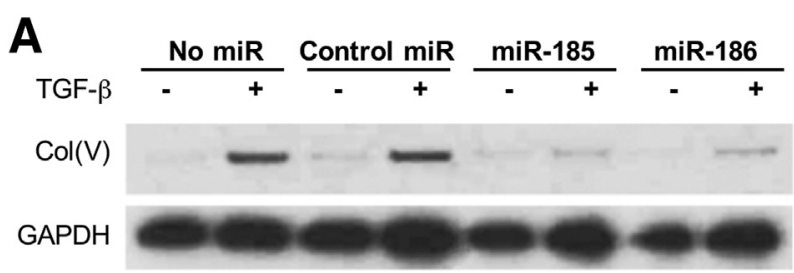

B

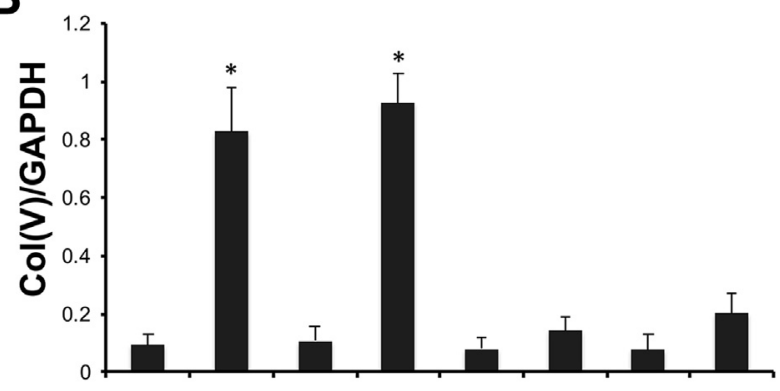

Figure 4 Mimics of miR-185 and miR-186 block transforming growth factor (TGF)- $\beta$-induced type 5 collagen $[\mathrm{Col}(\mathrm{V})]$ overexpression in A549 cells. A549 cells were transfected with miR-185 mimic, miR-186 mimic, or nontargeting control miRNA 6 hours before TGF- $\beta$ induction. Western blotting using anti-Col(V) and anti-glyceraldehyde-3-phosphate dehydrogenase (GAPDH) antibodies was performed after 24 hours of TGF- $\beta$ induction. A: Representative image of three independent experiments. B: Densitometry analysis of $\mathrm{Col}(\mathrm{V}) / \mathrm{GAPDH} .{ }^{*} P<0.05$ versus control.

in untransfected A549 cells and in A549 cells transfected with control miRNAs (Figure 5, A and B). In contrast, TGF$\beta$ induction caused only approximately $40 \%$ and $27 \%$ reduction of E-cadherin to $\alpha$-SMA ratio in A549 cells transfected with miR-185 mimic and miR-186 mimic, respectively. The results suggest that miR-185 and miR-186 alleviated TGF- $\beta$-induced EMT in A549 cells. The same experiment was repeated using HCC827 cells with similar results (Supplemental Figure S2).

\section{Discussion}

As a sequestered antigen, $\mathrm{Col}(\mathrm{V})$ is normally expressed in low levels and is hidden from the immune system. During $\mathrm{IPF}, \mathrm{Col}(\mathrm{V})$ is overexpressed in both mRNA and protein levels in the lungs. ${ }^{6}$ The anti-Col(V) immunity has been shown to play critical roles in the pathogenesis of IPF. ${ }^{6} \mathrm{~A}$ mechanistic understanding of $\mathrm{Col}(\mathrm{V})$ overexpression could be useful for the developments of biomarkers for early detection and treatment of IPF. The possible mechanisms leading to $\mathrm{Col}(\mathrm{V})$ overexpression include pretranscriptional mechanisms, such as genetic mutations, single-nucleotide polymorphism, DNA methylation and histone modifications, and posttranscriptional mechanisms such as miRNA regulations. In this study, we aimed to study the dysregulated miRNA related $\mathrm{Col}(\mathrm{V})$ overexpression during IPF, and found that miR-185 and miR-186 were significantly decreased in the lungs of patients with IPF (Figure 2). The direct interactions of miR-185 and miR-186 with COL5Al $3^{\prime}$-UTR were confirmed by using a $3^{\prime}$-UTR luciferase reporter assay (Figure 3). 

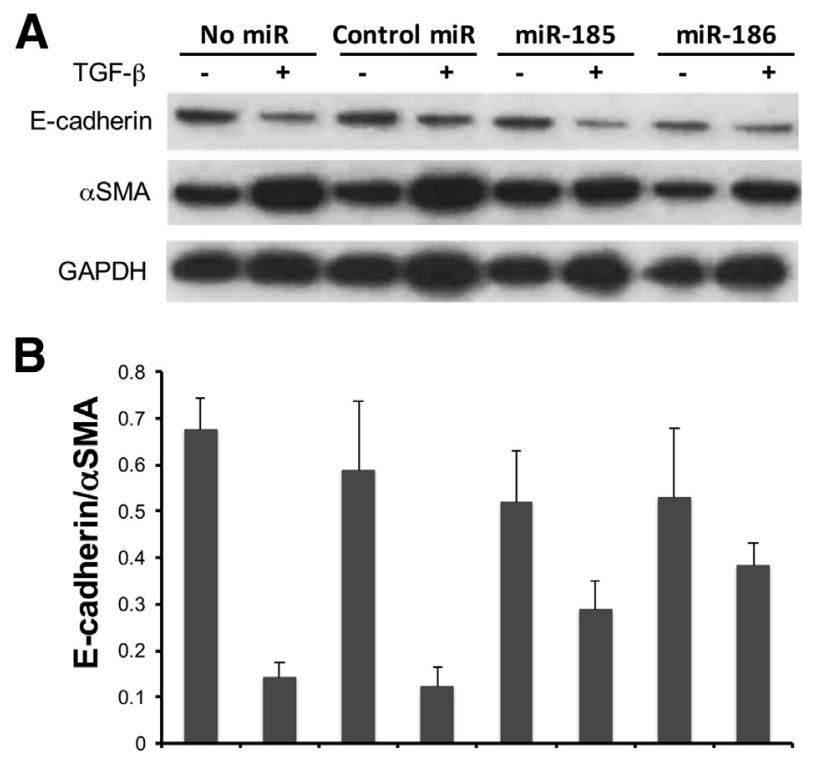

Figure 5 Mimics of miR-185 and miR-186 alleviate transforming growth factor (TGF)- $\beta$-induced epithelial-mesenchymal transition (EMT) in A549 cells. A549 cells were transfected with miR-185 mimic, miR-186 mimic, or nontargeting control miRNA 6 hours before TGF- $\beta$ induction. A: Western blotting using anti-E-cadherin and anti- $\alpha$-smooth muscle actin (SMA) antibodies was performed after 24 hours of TGF- $\beta$ induction. B: The density ratio of E-cadherin to $\alpha$-SMA of each specimen was calculated after densitometry analysis. The results are from the same experiment as Figure 4, and the Western blot shown is representative of three independent experiments. GAPDH, glyceraldehyde-3-phosphate dehydrogenase.

Furthermore, miR-185 and miR-186 were shown to prevent the TGF- $\beta$-induced $\mathrm{Col}(\mathrm{V})$ overexpression in a lung epithelial cell line. The biological roles of miR-185 and miR186 have been previously reported. Qadir et $\mathrm{al}^{17}$ reported that miR-185 inhibits tumor cell growth by targeting the phosphatase and tensin homolog/AKT signaling pathway. Antoniou et $\mathrm{al}^{18}$ showed that miR-186 inhibits myogenic differentiation; miR-186 has also been associated with replicative senescence in human lung fibroblast cells. ${ }^{19}$ Our study is the first to demonstrate the roles of miR-185 and miR-186 in Col(V) expression.

TGF- $\beta$ is known to signal through the Smad-mediated and non-Smad-mediated pathways, such as phosphatidylinositol 3-kinase/Akt, to induce the expression of fibrogenic genes such as collagens and smooth muscle actin. The effects of miR-185 and miR-186 on $\mathrm{Col}(\mathrm{V})$ expression in our study may be direct by targeting COL5A1 3'-UTR, and may also be indirect through the regulation of TGF- $\beta$ signaling pathways. The notion of indirect effects is supported by the recent report that miR-185 inhibits Akt phosphorylation in human hepatocellular carcinoma cells. ${ }^{17}$

In addition to inhibiting TGF- $\beta$-induced $\mathrm{Col}(\mathrm{V})$ overexpression, miR-185 and miR-186 also alleviated TGF$\beta$-induced EMT (Figure 5). There have been evidences indicating a pathogenesis role of EMT in IPF. Immunohistochemical staining of lung biopsies from IPF patients revealed fibroblast-like cells expressing the surfactant protein $\mathrm{C}$ that is normally synthesized and secreted by type II alveolar epithelial cells. ${ }^{20}$ Studies using lung biopsies from IPF patients showed significantly increased TGF- $\beta$ and $\alpha$ SMA expressions in type II alveolar epithelial cells and in fibroblastic foci. The E-cadherin expression was maintained in type II epithelial cell but was significantly decreased in bronchiolar basal cells in IPF. ${ }^{20-22}$ The anti-Col(V) immunity through $\mathrm{T}$ helper cell 17 -mediated inflammatory response has been shown to induce EMT in the disease model of obliterative bronchiolitis. It is conceivable that attenuated expressions of miR-185 and miR-186 lead to overexpression of $\mathrm{Col}(\mathrm{V})$, which in turn induces EMT through $\mathrm{T}$ helper cell $17-$ mediated inflammatory response in the IPF lungs. However, in our current in vitro study, miR-185 and miR-186 directly inhibited the TGF$\beta$-induced EMT without the participation of T helper cell 17 cells. This observation suggests that miR-185 and miR186 suppressed EMT directly independent of the anti$\mathrm{Col}(\mathrm{V})$ autoimmunity. This possibility is supported by previous reports of miR-185 and miR-186 inhibiting EMTrelated transcription factors STIM1 and TWIST1, respectively. ${ }^{23,24}$ Our data suggest that treatment strategies using miR-185 and miR-186 mimics may take effect through $\mathrm{Col}(\mathrm{V})$-dependent and $\mathrm{Col}(\mathrm{V})$-independent mechanisms.

Although the down-regulation of miR-185 and miR-186 correlated with $\mathrm{Col}(\mathrm{V})$ overexpression in the lungs, it did not correlate with disease severity of IPF. This is understandable since IPF pathogenesis mechanisms are multifaceted and are not limited to anti-Col(V) autoimmunity. On the other hand, the consistent attenuation of miR-185 and miR-186 not related to disease severity makes them good candidates for early diagnostic biomarkers. Diagnosis of IPF is usually not straightforward even with extensive physiological and radiological studies. In patients failing to demonstrate a typical IPF pattern on their chest radiographs, IPF is diagnosed on the basis of surgical lung biopsy, which is an invasive procedure with several known complications, including persistent air leak, prolonged mechanical ventilation, pneumonia, and acute exacerbation of IPF. ${ }^{25,26}$ Furthermore, pathological diagnosis of IPF on surgical lung biopsy can be challenging as varied levels of confidence in the pathological diagnosis of IPF/UIP exist and some patients may demonstrate an unclassifiable fibrotic pattern. A reliable biomarker for diagnosis of IPF is needed. The relatively stable nature of miRNAs makes them ideal candidates for biomarker development. Current study suggests that miR-185 and miR-186 could be used as biomarkers on lung tissue for IPF. Future study will include determining miR-185 and miR-186 levels in serum of IPF patients and controls. This could enable identification of viable circulating biomarkers for early detection of IPF and would possibly eliminate the need for an invasive lung biopsy in patients with characteristic symptoms.

In summary, our study showed that expression levels of miR-185 and miR-186 were significantly decreased in the lungs of IPF patients, and the levels of expression did not correlate with disease severity. In addition to regulating the 
expression of COL5Al, miR-185 and miR-186 also prevented TGF- $\beta$-induced $\mathrm{Col}(\mathrm{V})$ expression and EMT. Results of this study provided basis for the development of a pathogenesis-related biomarker and therapeutic target for IPF.

\section{Supplemental Data}

Supplemental material for this article can be found at http://dx.doi.org/10.1016/j.ajpath.2016.04.015.

\section{References}

1. Gribbin J, Hubbard RB, Le Jeune I, Smith CJ, West J, Tata LJ: Incidence and mortality of idiopathic pulmonary fibrosis and sarcoidosis in the UK. Thorax 2006, 61:980-985

2. Olson AL, Swigris JJ, Lezotte DC, Norris JM, Wilson CG, Brown KK: Mortality from pulmonary fibrosis increased in the United States from 1992 to 2003. Am J Respir Crit Care Med 2007, 176:277-284

3. Raghu G, Weycker D, Edelsberg J, Bradford WZ, Oster G: Incidence and prevalence of idiopathic pulmonary fibrosis. Am J Respir Crit Care Med 2006, 174:810-816

4. Takagishi T, Ostrowski R, Alex C, Rychlik K, Pelletiere K, Tehrani R: Survival and extrapulmonary course of connective tissue disease after lung transplantation. J Clin Rheumatol 2012, 18:283-289

5. Parra ER, Teodoro WR, Velosa AP, de Oliveira CC, Yoshinari NH, Capelozzi VL: Interstitial and vascular type V collagen morphologic disorganization in usual interstitial pneumonia. J Histochem Cytochem 2006, 54:1315-1325

6. Vittal R, Mickler EA, Fisher AJ, Zhang C, Rothhaar K, Gu H, Brown KM, Emtiazdjoo A, Lott JM, Frye SB, Smith GN, Sandusky GE, Cummings OW, Wilkes DS: Type V collagen induced tolerance suppresses collagen deposition, TGF-beta and associated transcripts in pulmonary fibrosis. PLoS One 2013, 8:e76451

7. Yoshida S, Haque A, Mizobuchi T, Iwata T, Chiyo M, Webb TJ, Baldridge LA, Heidler KM, Cummings OW, Fujisawa T, Blum JS, Brand DD, Wilkes DS: Anti-type V collagen lymphocytes that express IL-17 and IL-23 induce rejection pathology in fresh and well-healed lung transplants. Am J Transplant 2006, 6:724-735

8. Vittal R, Fan L, Greenspan DS, Mickler EA, Gopalakrishnan B, Gu H, Benson HL, Zhang C, Burlingham W, Cummings OW, Wilkes DS: IL17 induces type $\mathrm{V}$ collagen overexpression and EMT via TGF-betadependent pathways in obliterative bronchiolitis. Am J Physiol Lung Cell Mol Physiol 2013, 304:L401-L414

9. Suzuki H, Lasbury ME, Fan L, Vittal R, Mickler EA, Benson HL, Shilling R, Wu Q, Weber DJ, Wagner SR, Lasaro M, Devore D, Wang Y, Sandusky GE, Lipking K, Pandya P, Reynolds J, Love R, Wozniak T, Gu H, Brown KM, Wilkes DS: Role of complement activation in obliterative bronchiolitis post-lung transplantation. $\mathrm{J}$ Immunol 2013, 191:4431-4439

10. Burlingham WJ, Love RB, Jankowska-Gan E, Haynes LD, Xu Q, Bobadilla JL, Meyer KC, Hayney MS, Braun RK, Greenspan DS, Gopalakrishnan B, Cai J, Brand DD, Yoshida S, Cummings OW, Wilkes DS: IL-17-dependent cellular immunity to collagen type V predisposes to obliterative bronchiolitis in human lung transplants. J Clin Invest 2007, 117:3498-3506

11. Broderick JA, Zamore PD: MicroRNA therapeutics. Gene Ther 2011, 18:1104-1110

12. Dakhlallah D, Batte K, Wang Y, Cantemir-Stone CZ, Yan P, Nuovo G, Mikhail A, Hitchcock CL, Wright VP, Nana-Sinkam SP, Piper MG,
Marsh CB: Epigenetic regulation of miR-17 92 contributes to the pathogenesis of pulmonary fibrosis. Am J Respir Crit Care Med 2013, 187:397-405

13. Lino Cardenas CL, Henaoui IS, Courcot E, Roderburg C, Cauffiez C, Aubert S, Copin MC, Wallaert B, Glowacki F, Dewaeles E, Milosevic J, Maurizio J, Tedrow J, Marcet B, Lo-Guidice JM, Kaminski N, Barbry P, Luedde T, Perrais M, Mari B, Pottier N: miR$199 a-5 p$ is upregulated during fibrogenic response to tissue injury and mediates TGFbeta-induced lung fibroblast activation by targeting caveolin-1. PLoS Genet 2013, 9:e1003291

14. Das S, Kumar M, Negi V, Pattnaik B, Prakash YS, Agrawal A, Ghosh B: MicroRNA-326 regulates profibrotic functions of transforming growth factor-beta in pulmonary fibrosis. Am J Respir Cell Mol Biol 2014, 50:882-892

15. Milosevic J, Pandit K, Magister M, Rabinovich E, Ellwanger DC, Yu G, Vuga LJ, Weksler B, Benos PV, Gibson KF, McMillan M, Kahn M, Kaminski N: Profibrotic role of miR-154 in pulmonary fibrosis. Am J Respir Cell Mol Biol 2012, 47:879-887

16. Delacoux F, Fichard A, Geourjon C, Garrone R, Ruggiero F: Molecular features of the collagen V heparin binding site. J Biol Chem 1998, 273:15069-15076

17. Qadir XV, Han C, Lu D, Zhang J, Wu T: miR-185 inhibits hepatocellular carcinoma growth by targeting the DNMT1/PTEN/Akt pathway. Am J Pathol 2014, 184:2355-2364

18. Antoniou A, Mastroyiannopoulos NP, Uney JB, Phylactou LA: miR186 inhibits muscle cell differentiation through myogenin regulation. J Biol Chem 2014, 289:3923-3935

19. Lee YH, Kim SY, Bae YS: Upregulation of miR-760 and miR-186 is associated with replicative senescence in human lung fibroblast cells Mol Cells 2014, 37:620-627

20. Marmai C, Sutherland RE, Kim KK, Dolganov GM, Fang X, Kim SS Jiang S, Golden JA, Hoopes CW, Matthay MA, Chapman HA Wolters PJ: Alveolar epithelial cells express mesenchymal proteins in patients with idiopathic pulmonary fibrosis. Am J Physiol Lung Cell Mol Physiol 2011, 301:L71-L78

21. Morbini P, Inghilleri S, Campo I, Oggionni T, Zorzetto M, Luisetti M: Incomplete expression of epithelial-mesenchymal transition markers in idiopathic pulmonary fibrosis. Pathol Res Pract 2011, 207:559-567

22. Lomas NJ, Watts KL, Akram KM, Forsyth NR, Spiteri MA: Idiopathic pulmonary fibrosis: immunohistochemical analysis provides fresh insights into lung tissue remodelling with implications for novel prognostic markers. Int J Clin Exp Pathol 2012, 5:58-71

23. Zhang Z, Liu X, Feng B, Liu N, Wu Q, Han Y, Nie Y, Wu K, Shi Y, Fan D: STIM1, a direct target of microRNA-185, promotes tumor metastasis and is associated with poor prognosis in colorectal cancer. Oncogene 2015, 34:4808-4820

24. Zhu X, Shen H, Yin X, Long L, Xie C, Liu Y, Hui L, Lin X, Fang Y, Cao Y, Xu Y, Li M, Xu W, Li Y: miR-186 regulation of Twist1 and ovarian cancer sensitivity to cisplatin. Oncogene 2016, 35:323-332

25. Raghu G, Collard HR, Egan JJ, Martinez FJ, Behr J, Brown KK, Colby TV, Cordier JF, Flaherty KR, Lasky JA, Lynch DA, Ryu JH, Swigris JJ, Wells AU, Ancochea J, Bouros D, Carvalho C, Costabel U, Ebina M, Hansell DM, Johkoh T, Kim DS, King TE Jr, Kondoh Y, Myers J, Muller NL, Nicholson AG, Richeldi L, Selman M, Dudden RF, Griss BS, Protzko SL, Schunemann HJ; ATS/ERS/JRS/ALAT Committee on Idiopathic Pulmonary Fibrosis: An official ATS/ERS/JRS/ALAT statement: idiopathic pulmonary fibrosis: evidence-based guidelines for diagnosis and management. Am J Respir Crit Care Med 2011, 183:788-824

26. Park JH, Kim DK, Kim DS, Koh Y, Lee SD, Kim WS, Kim WD, Park SI: Mortality and risk factors for surgical lung biopsy in patients with idiopathic interstitial pneumonia. Eur J Cardiothorac Surg 2007, 31:1115-1119 